\title{
Research progress on the PI3K/AKT signaling pathway in gynecological cancer (Review)
}

\author{
XIANG SHI $^{1}$, JINGJING WANG $^{1}$, YU LEI $^{1}$, CAOFAN CONG $^{1}$, DAILIN TAN $^{2}$ and XIANRONG ZHOU ${ }^{1}$ \\ Departments of ${ }^{1}$ Pathology and ${ }^{2}$ Clinical Laboratory, Qianjiang Central Hospital, Qianjiang, Hubei 433100, P.R. China
}

Received August 15, 2018; Accepted February 21, 2019

DOI: $10.3892 / \mathrm{mmr} .2019 .10121$

\begin{abstract}
The phosphatidylinositol 3-kinase (PI3K)/protein kinase $\mathrm{B}(\mathrm{AKT})$ signaling pathway is involved in the regulation of multiple cellular physiological processes by activating downstream corresponding effector molecules, which serve an important role in the cell cycle, growth and proliferation. This is a common phenomenon; overactivation of the pathway is present in human malignancies and has been implicated in cancer progression, hence one of the important approaches to the treatment of tumors is rational drug design using molecular targets in the PI3K/AKT signaling pathway. In brief, the present review analyzed the effects of the PI3K/AKT signaling pathway on certain gynecological cancer types.
\end{abstract}

\section{Contents}

1. Introduction

2. Composition and function of the PI3K/AKT signaling pathway

3. Association between PI3K/AKT and endometrial cancer

4. Association between PI3K/AKT and cervical cancer

5. Association between PI3K/AKT and ovarian cancer

6. Current status of treatment for the PI3K/AKT signaling pathway

7. Conclusion

Correspondence to: Professor Xianrong Zhou, Department of Pathology, Qianjiang Central Hospital, 22 Zhang Hua Street, Qianjiang, Hubei 433100, P.R. China

E-mail: zhouxianrong08@126.com

Abbreviations: EGF, epidermal growth factor; RTK, receptor tyrosine kinase; PTEN, phosphatase and tensin homolog; PDK1, 3-phosphoinositol-dependent protein kinase-1; TSC2, TSC complex subunit 2; LKB1, serine/threonine kinase 11; HCCR-1, human cervical cancer oncogene 1

Key words: gynecological cancer, phosphatidylinositol 3-kinase, protein kinase $\mathrm{B}$, mechanistic target of rapamycin kinase

\section{Introduction}

With the deterioration of the current global environment, particularly in developing countries, three common gynecological tumors (cervical cancer, endometrial cancer and ovarian cancer) have become major threats to women's health (1). Therefore, it is important to actively investigate the underlying molecular mechanisms and potential therapeutic targets associated with such tumors. Phosphatidylinositol 3-kinase $(\mathrm{PI} 3 \mathrm{~K}) /$ protein kinase $\mathrm{B}$ (AKT) is one of the signaling pathways proven to serve an important role in regulating cell proliferation, the cell cycle and apoptosis (2). A number of studies suggest that the PI3K/AKT signaling pathway is associated with certain gynecological tumors (3-5), and the rational design of molecular targets for the PI3K/AKT signaling pathway is also an important option for the treatment of tumors. Therefore, the present study reveals the association between the PI3K/AKT signaling pathway and the occurrence and development of certain gynecological tumors by summarizing relevant research and drawing conclusions.

\section{Composition and function of the PI3K/AKT signaling pathway}

PI3K is a member of the lipid kinases family, which are activated by phosphorylating the 3-hydroxyl group of the inositol ring of phosphatidylinositol (PtdIns) lipids in the plasma membrane (6). PI3K may be divided into three categories according to its preference for lipid substrates and different structures (7). Among them, type I PI3K serves an important role in tumors, and is the subtype that has been studied most thoroughly. The type I PI3K is composed of p110. A heterodimer consisting of a catalytic subunit of p110 and a regulatory subunit $\mathrm{p} 85$, wherein there are seven regulatory subunits produced by different genes and gene combinations: $\mathrm{p} 85 \alpha, \mathrm{p} 85 \beta, \mathrm{p} 55 \alpha, \mathrm{p} 55 \gamma, \mathrm{p} 50 \alpha, \mathrm{p} 101$ and $\mathrm{p} 87$. The catalytic subunit (p110) has four subtypes, p110 $\alpha, \mathrm{p} 110 \beta, \mathrm{p} 110 \gamma$, and p1108 (7). Typically, the catalytic subunit (p110) binds to the regulatory subunit to stabilize the protein heterodimer and inhibit the activation of PI3K (8). PI3K is normally activated by extracellular signals under physiological conditions, and there are two principal activation pathways, involving interaction with a factor receptor of a phosphorylated tyrosine residue to induce heterodimer conformational changes and activation (9). Various stimuli, including growth factors, 
cytokines and hormones, have been reported to activate PI3K. In particular, epidermal growth factor (EGF), platelet-derived growth factor and insulin-like growth factor $(10,11)$ bind to the corresponding transmembrane receptor tyrosine kinase (RTK) region of the N-terminal extracellular domain, resulting in autophosphorylation of tyrosine residues in the cytoplasmic region of the RTK and the linker molecule, followed by $\mathrm{p} 85 \mathrm{SH} 2$. The interaction between the domain and the phospho-Tyr residue on the RTK complex recruits PI3K to RTKs, resulting in the allosteric activation of PI3K (8). In addition to RTKs, G-protein coupled receptors are another important class of classical upstream regulators that activate PI3K, the most common being p110 $\beta$ (12). Furthermore, PI3K may be directly or indirectly activated by the catalytic subunit (p110) in combination with small GTPases, including Ras and Ras-related protein Rab-5A $(9,12)$.

According to previous studies, among the four type I catalytic subunits, only phosphatidylinositol-4,5-bisphosphate 3-kinase catalytic subunit alpha (PIK3CA) is frequently mutated in human cancer $(13,14)$. Although there are numerous mutations in PIK3CA, only two sites have been found to cause an increase in PI3K activity through different mechanisms (15). The ubiquitously expressed PIK3CB is less frequently mutated (16), likely due to the unique regulatory pattern present between the catalytic subunit and the regulatory subunit (17). Mutations in the type I regulatory subunit gene (PIK3R1 or PIK3R2) have been identified in cancer cells and cause an increase in PI3K activity, and it has been demonstrated through cell transformation experiments that PIK3CA serves a key role in the potential carcinogenesis of PIK3R1 mutants (18-20). Moreover, p110 $\alpha$ serves an important role in inducing tumor angiogenesis. Studies have demonstrated that after knocking out the p110 $\alpha$ gene, embryonic development is slow and fetal vascular formation is defective in the second trimester (21-23). In cancer cells with the wild-type PI3K gene, which causes constitutive signal transduction by $\mathrm{PI} 3 \mathrm{~K}$, there is usually carcinogenic damage caused by the upstream tyrosine kinase or Ras (14). Phosphatase and tensin homolog (PTEN) lipid phosphatase or inositol polyphosphate-4-phosphatase type II B deletion is another pathway for elevated PI3K lipid products, but the inactivation of these tumor suppressors is not mutually exclusive with mutations in the PI3K or Ras genes $(12,19)$. Mouse models have also demonstrated that the loss of PTEN and the PIK3CA mutation together may lead to the development of ovarian cancer (24). There are a number of polymerization targets that receive signals generated by the PI3K downstream cascade, but the most important mediator is the serine/threonine kinase AKT (8); AKT serves a dominant role in the signal transduction of the entire PI3K pathway.

There are three subtypes of the serine/threonine kinase AKT in mammals, AKT1, AKT2 and AKT3, which are key molecules in the PI3K signal transduction pathway (25). The amino acid structure of AKT, from the N-terminus to the C-terminus, includes a plekstrin homology (PH) domain, the central catalytic domain and the carboxy-terminal regulatory domain. The $\mathrm{PH}$ domain primarily mediates membrane translocation following AKT activation; the catalytic domain contains ATP binding sites. Activation of AKT is dependent on the phosphorylation of its internal Thr308 site; the regulatory domain at the carboxy terminus contains a large amount of proline, containing another phosphorylated Ser473 site required for AKT activation (26-28). In the classical PI3K/AKT activation mode, AKT and the upstream 3-phosphoinositol-dependent protein kinase-1 (PDK1) are recruited into the cell membrane via the interaction of the $\mathrm{PH}$ domain with PtdIns (3-5) P3 (PIP3) in PI3K, and phosphorylation of AKT by activation of the Thr308 site in the T-loop by PDK1 (29). The activated phosphorylated AKT is transported from the cell membrane to other regions of the cell to phosphorylate multiple downstream substrates to achieve AKT function (30). Phosphorylation of AKT is considered to be isoform-specific (31). Furthermore, activation and stabilization of AKT is regulated by the phosphorylation of multiple sites, apart from the two major sites, Thr308 and Ser473. AKT1 has 31 potential phosphorylation sites, AKT2 has 22 phosphorylation sites, and AKT3 has 18 phosphorylation sites; with future studies, the number of potential phosphorylation sites for AKT may increase even further.

The PI3K/AKT signaling pathway is frequently in a dysregulated state in tumors, and has now become an important anticancer target (32). The PI3K/AKT signaling pathway itself serves a major role in regulating cell physiology and pathology, including cell proliferation, survival and invasion (Fig. 1). Some of the activating mutations in PI3K/AKT are also common in human tumors, and thus may promote tumor growth (2,33). Additionally, the replacement of E17K by a single amino acid in the $\mathrm{PH}$ domain of AKT results in the recruitment of constitutive AKT to the cell membrane (34). Therefore, in recent years, drug targets for PI3K or AKT have been widely developed and clinical trials have been conducted. It follows that the PI3K/AKT signaling pathway is closely associated with tumor development and has garnered much attention.

\section{Association between PI3K/AKT and endometrial cancer}

Specifically, $>80 \%$ of endometrial cancer cases have at least one somatic alteration that affects signaling pathways, and the PI3K/AKT signaling pathway is one of the most frequently altered biochemical pathways in endometrial cancer (35). Statistics indicate that $\sim 90 \%$ of young endometrial cancer patients have high progesterone receptor expression and exhibit resistance to progesterone therapy (36), and it has also been demonstrated that high activation of the $\mathrm{PI} 3 \mathrm{~K} / \mathrm{AKT} / \mathrm{mechanistic}$ target of rapamycin kinase (mTOR) signaling pathway is essential for the progression of endometrial cancer (37). When inhibiting the phosphorylation of mTOR, it has a marked inhibitory effect on the proliferation of endometrial cancer (38). In addition, studies have suggested that the dysregulation of mTOR in primary endometrial cancer may also be associated with the loss of TSC complex subunit 2 (TSC2) and serine/threonine kinase 11 (LKB1) expression (39). Other studies also demonstrated that activation of mTOR complex 2 (mTORC2) and the phosphorylation of AKT are also upregulated in endometrial cancer, suggesting that the rapamycin-insensitive mTORC2 pathway may be involved in the development of endometrial cancer (40). These conclusions suggest that the PI3K/AKT signaling pathway serves a key role in endometrial cancer. 


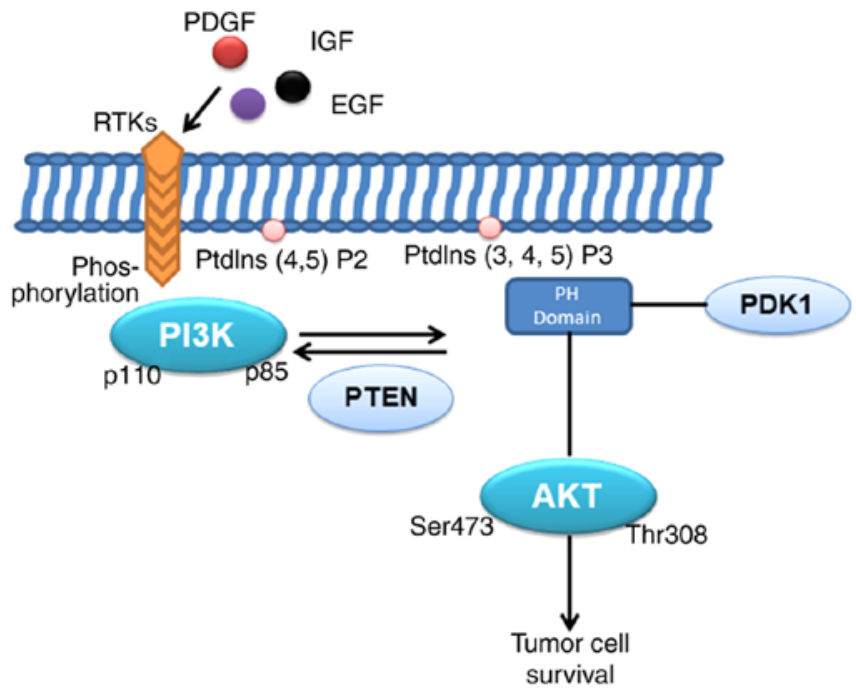

Figure 1. Schematic of the PI3K/AKT signaling pathway. RTK recruits PI3K following activation and phosphorylation, and phosphorylates PtdIns $(4,5)$ P2 to PtdIns (3-5) P3, which activates AKT by recruiting PDK1 to the $\mathrm{PH}$ domain of AKT, thereby activating the entire pathway and regulating cell growth. PI3K, phosphatidylinositol 3-kinase; AKT, protein kinase B; RTK, receptor tyrosine kinase; PtdIns, phosphatidylinositol; PDK1, 3-phosphoinositol-dependent protein kinase-1; PH, plekstrin homology; PTEN, phosphatase and tensin homolog; PDGF, platelet derived growth factor; IGF, insulin-like growth factor; EGF, epidermal growth factor.

According to the molecular spectrum of endometrial cancer reported by The Cancer Genome Atlas in 2013 (41), four major molecular spectra were analyzed and identified in the genome, transcriptome and proteome based on array and sequencing technology: DNA polymerase- $\varepsilon$ (POLE; super mutation), microsatellite instability (hypermutation), low copy number (endometrioid) and high copy number (serous). In general, the mutation rates of PI3KCA, PIK3R1, AKT1 and PTEN in endometrial cancer in all cases collected were 59.7, 33, 3.2 and $66 \%$, respectively, and the PIK3R1, AKT1 and PTEN mutation rates in the POLE group were the highest, reaching 94, 71 and $65 \%$, respectively.

An important negative regulator in the PI3K pathway is PTEN, which is located on chromosome 10q23 and encodes a protein with tyrosine kinase functions (42). PTEN has lipid and protein phosphatase activity, which leads to cell cycle arrest at the G2/S checkpoint and inhibits PI3 phosphorylation by dephosphorylation of PIP3 to phosphatidylinositol 4,5-bisphosphate, leading to a decrease in intracellular PtdIns levels and affecting downstream AKT signaling pathways (43); simultaneously, the PTEN-encoded protein phosphatase inhibits cell proliferation and migration, and thus the loss of PTEN activity may result in abnormal cell growth and apoptosis escape. Inactivation of PTEN may be due to gene mutations, promoter methylation or protein degradation, leading to loss of expression or a mild loss of heterozygosity (44-48). However, according to statistics, $20 \%$ of cases of endometrial hyperplasia, $55 \%$ of precancerous lesions, and 35-80\% of endometrial cancer cases have PTEN mutations (49). The molecular mechanisms involved in PTEN mutations may further suggest that the PI3K/AKT signaling pathway is involved in the early events of endometrial cancer and promotes the conversion of precancerous lesions into tumors.

\section{Association between PI3K/AKT and cervical cancer}

The presence of AKT hyperphosphorylation in cervical cancer specimens suggests a constitutive activation of the PI3K/AKT pathway in cervical cancer (50). The existence of an association between HPV and cervical cancer has long been under consensus, and mTOR inhibitors blocked the phosphorylation of eukaryotic translation initiation factor 4E-binding protein 1 and markedly reduced the expression level of human papillomavirus E7 protein in an in vitro model, leading to the aggregation of cells in the G1 phase and the induction of apoptosis (51). Moreover, studies have reported that changes in genes related to the PI3K/AKT pathway are associated with an incomplete metabolic response following chemoradiation in cervical cancer, and that PIK3CA-activating mutations are associated with long-term survival post-radiotherapy $(52,53)$. The most common PIK3CA mutation in cervical cancer is in E545K, a tumor-associated mutation site in the helical domain of the p1 $10 \alpha$ catalytic subunit of PI3K, which may lead to constitutive PI3K activation and enhance tumorigenicity (54-56). C420R in PIK3CA may also induce oncogenic conversion by promoting the membrane binding of p110 $\alpha$ (57). Activation of the PI3K/AKT pathway is ubiquitous in various cancer types, and the carcinogenic effects of PIK3CA mutations have been widely accepted as evidence for preclinical diagnosis; however, the PIK3CA mutation is not effective as a biomarker in obese patients with cervical cancer, which may be due to obesity-associated factors affecting the transduction of relevant molecules in the PI3K signaling pathway $(58,59)$.

Currently, $\sim 99 \%$ of cases of cervical cancer are caused by high-risk HPV (60), and HPV E7 and E6 oncoproteins are essential for promoting cervical cancer. Carcinogenic HPV E6 also rapidly degrades TSC, causing TORC1 and mTOR signaling downstream of PI3K/AKT to be activated (61). Similarly, the tumor suppressor gene LKB1 has been demonstrated to be defective in cervical cancer HeLa cells, and inhibits mTOR by TSC2 stimulation, and the activation of the PI3K/AKT pathway has been observed in cervical cancer cell lines and immunodeficient mouse xenograft models (62). In a Phase I study, PI3K mutations were observed in 15 patients with cervical cancer, 5 of whom experienced significant treatment efficacy with drugs targeting the PI3K/AKT/mTOR pathway. Rashmi et al (53) reported that the mutational profile of the PI3K/Akt signaling pathway in cervical cancer tissues is complex; the use of AKT inhibitors to effectively inhibit mTORC1/2 may reduce glucose absorption and glycolysis, and decrease cell viability in vitro, thereby increasing the chemosensitivity of cervical cancer. Human cervical cancer oncogene 1 (HCCR-1) is composed of 9 exons and a conserved intron/exon, which is abnormally expressed in cervical cancer cells, contains a TATA box and a CAAT box, and is identified as the putative DNA binding site of TCF/LEF-1 (63). To determine the function of PI3K on the HCCR promoter, a vector containing pCDNA3-PI3K was transfected into $\mathrm{NIH} / 3 \mathrm{~T} 3$ cells, and the promoter activity in PI3K-transfected cells was 1.72 times that of cells transfected with the vector alone. Additionally, vectors containing wild-type AKT and dominant-negative AKT cDNA were transfected into K562 cells, and the results indicated that wild-type AKT enhanced HCCR-1 promoter activity (64). These data indicated that 
alterations in the PI3K/AKT signaling pathway affect HCCR expression, and HCCR is one of the downstream components of the PI3K/AKT pathway, further indicating that the PI3K/AKT signaling pathway affects the development and progression of cervical cancer.

\section{Association between PI3K/AKT and ovarian cancer}

Ovarian cancer is a type of malignancy that poses a serious threat to female health worldwide, according to recent statistics $(65,66)$. In general, the PI3K/AKT signaling pathway is dysregulated in ovarian cancer, and $\sim 12 \%$ of ovarian cancer cases present with mutations in PIK3CA $(67,68)$. High-grade serous ovarian cancer is the most important subtype of ovarian cancer, and $\sim 50 \%$ of patients have activations inPIK3CA. In addition, mutations in PI3K also appear to be associated with the histology of ovarian cancer. In cases analyzed previously, 20\% had amplifications in PIK3CA, and 5\% of the three AKT subtypes presented with PTEN deletion $(67,69)$. Studies in a mouse model have demonstrated that ovarian cancer is triggered by the activation of PIK3CA mutations and a PTEN deletion, and that inhibition of PI3K/mTOR may prolong tumor growth and survival. The expression levels of p-AKT and PIK3CA are associated with ovarian cancer survival, and the activation status of the PI3K/AKT pathway is considered to be an independent prognostic marker in ovarian cancer (as measured by AKT and mTOR phosphorylation levels) (70,71); PIK3CA mutations predict the response to PI3K and mTOR inhibitors (72). A study also reported that alterations in the gene copy number of the catalytic subunits $\mathrm{p} 110 \alpha$ and $\mathrm{p} 110 \beta$ of PI3K are associated with poor prognosis in ovarian cancer (73).

Polycyclic aromatic hydrocarbons, which are environmental toxins, are known to be reproductive toxins, which cause primary follicle atresia and premature ovarian failure. It has been reported that treatment with the PI3K inhibitor LY294002 may prevent follicular atresia (74). In the face of toxic follicle destruction, follicles attempt to induce cell survival by upregulating the PI3K/AKT/mTOR pathway, which in turn leads to increased follicle proliferation, consuming reserves of primitive ovarian follicles (75). Therefore, the PI3K/AKT/mTOR pathway in ovarian cancer may be used as a predictor of damage to primordial follicles during normal oocyte maturation (75). The function of the PI3K/AKT pathway in ovarian cancer is very complex, with two major alterations: Various alterations in the PI3K/AKT pathway itself, and different effects on the PI3K/AKT pathway. Through these modifications, PI3K/AKT has been demonstrated to serve a key role in ovarian cancer development, progression and chemoresistance. This complexity, which begins with PI3K/AKT dysregulation, may be due to overactivation and mutations in the catalytic domain and regulatory domain mutations, or the modification of downstream targets of PI3K (76). In the development and progression of ovarian cancer, it is clear that the PI3K/AKT pathway serves an important role in the complex phenotype of ovarian cancer in unique ways, many of which may be highly invasive. In serous carcinoma or low-grade endometrial ovarian cancer, mutations in the pathway may contribute to cell proliferation, invasion and migration by modifying cell cycle inhibitors and matrix metalloproteinases (77).

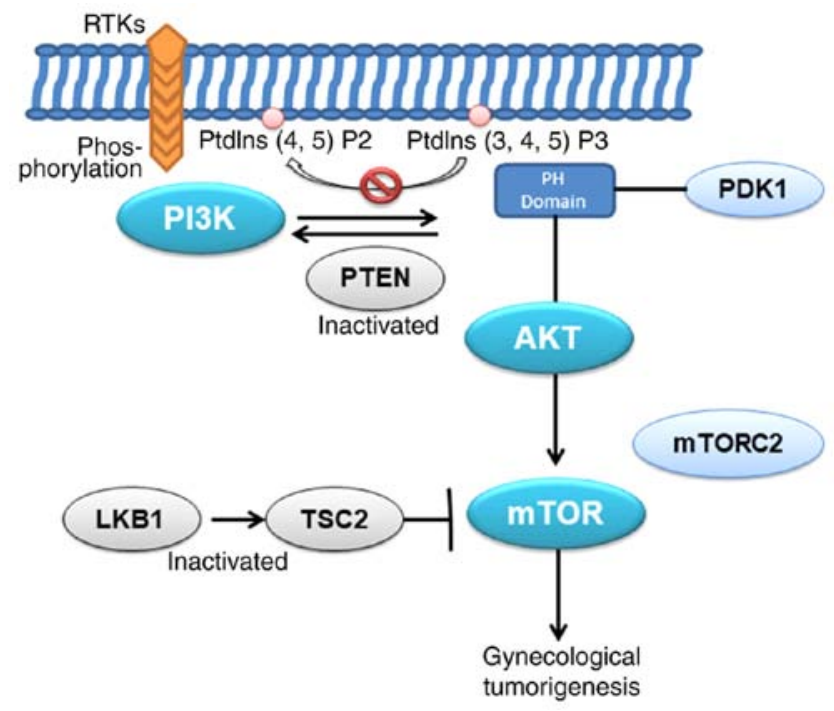

Figure 2. Effect of the PI3K/AKT signaling pathway on gynecological tumors. By inactivating PTEN, LKB1 and other regulatory factors, the phosphorylation levels of associated molecules in the PI3K/AKT pathway are altered, and the activity of downstream mTOR is further changed, thereby triggering the occurrence of gynecological cancer. PI3K, phosphatidylinositol 3-kinase; AKT, protein kinase B; RTK, receptor tyrosine kinase; PtdIns, phosphatidylinositol; PDK1, 3-phosphoinositol-dependent protein kinase-1; $\mathrm{PH}$, plekstrin homology; PTEN, phosphatase and tensin homolog; LKB1, serine/threonine kinase 11; TSC2, TSC complex subunit 2; mTOR, mechanistic target of rapamycin kinase; mTORC, mTOR complex 2 .

\section{Current status of treatment for the PI3K/AKT signaling pathway}

To date, various PI3K-associated inhibitors with isomeric properties have been tested in various tumors, although a number of these drugs have not yet been used in clinical practice, including GDC0941, XL147, BKM120, NVP-BYL719 (p110 $\alpha$ specificity), SAR260301 (P110 $\beta$ specificity) and TGR-1202 (p110 $\beta$ specificity) (12,78). PI3K and mTOR are structurally similar, and there are currently many studies in progress on dual inhibitors of PI3K and mTOR, such as NVP-BEZ235, GDC-0980 and XL765, which may be able to overcome the limitations of single kinase inhibition via the feedback loop (12,78-80). In addition, different AKT subtypes mediate different pathophysiological changes in tumors, including AKT1, which primarily mediates tumorigenesis and early development, whereas AKT2 appears to primarily promote tumor metastasis $(81,82)$. Thus the investigation of specific inhibitors of AKT isoforms is also a promising strategy for the treatment of tumors. Up to now, the standard drugs targeting the PI3K/AKT pathway, widely used in clinical practice, have been downstream mTOR blockers, including temsirolimus and everolimus. Comprehensive clinical studies have demonstrated that the overall efficiency of mTOR blockers varies from $4-24 \%$ (83). In clinical trials of ovarian cancer, it was reported in five cases that sirolimus may be more effective in the treatment of clear cell ovarian cancer (84). The second generation of mTOR blockers is also under development. It is reported that second-generation mTOR blockers contain two protein complexes, TORC1 and TORC2, which simultaneously inhibit mTORC1 and mTORC2, thereby reducing the influence of negative feedback AKT phosphorylation; with this, the therapeutic effect is likely to be better, and less resistance will 
occur (85). With ongoing research, the prospect of drug targets for the PI3K/AKT pathway is becoming a focus for tumor treatment.

With the development of new knowledge, in addition to the aforementioned more classical mTOR inhibitors, the targeted treatment of PI3K/AKT has been gradually enriched. Previous studies have identified multiple genetic alterations in gynecological tumors, including PTEN loss, ARID1A mutations, ERBB2 overexpression, and the mutation of PI3K/AKT (86). Excessive activation of PI3K/AKT may produce resistance to tumors, including endometrial cancer, targeting RTK inhibitors of EGFR and VEGF, thus drug sensitivity increases markedly following targeted reduction of this resistance (87-89). Targeted inhibitors of PI3K, BKM120 and MK-2206, have demonstrated antitumor activity, while MK-2260 exhibits limited single-agent activity in wild-type and mutant PIK3CA, and this positive role is undoubtedly encouraging (90). In addition, comprehensive genomic analysis of metastatic cervical cancer has produced important findings for the identification of novel therapeutic targets and the targeted treatment of cervical cancer; studies have demonstrated that the use of FGFR tyrosine kinase inhibitors in patients with FGFR3-TACC3 fusion expression has achieved good results and it has been suggested that FGFR3-TACC3 gene fusion activation is associated with the HPV-induced carcinogenesis-related FGFR pathway, and these molecular alterations involve the PI3K/AKT/mTOR and RAF proto-oncogene/MEK pathways $(91,92)$. Since 2012, CRISPR has been an active part of cancer research as a powerful gene editing technique, used for cutting target DNA. Studies have demonstrated that in PTEN wild-type endometrial cancer cells, the use of CRISPR/Cas9 to cut PTEN, as a negative regulator of PI3K/AKT, may enhance the inhibition of cells by a combination of PARP/PI3K (93); this reveals that CRISPR/Cas9 may be a useful technology in cancer therapy.

\section{Conclusion}

$\mathrm{PI} 3 \mathrm{~K} / \mathrm{AKT}$ is one of most important signal transduction pathways, which is involved in cell proliferation, cell cycle regulation, apoptosis and other relevant pathophysiological processes, and serves a key role in the occurrence and development of tumors (Fig. 2). Therefore, it is feasible that relevant drug molecules may be used to block or inhibit the PI3K/AKT signaling pathway to facilitate the identification of anti-tumor targets. The specific function of each molecular site and domain of the pathway in different tumors remains obscure and requires investigation in future research; however, targeted drugs for each subunit and site have gained further development and verification. With the deepening elucidation of the underlying mechanism by numerous studies, it is considered that drug targets for the PI3K/AKT signaling pathway will become effective clinical therapeutic approaches in cancer prevention and treatment.

\section{Acknowledgements}

The authors would like to thank Dr Ping He (Department of Clinical Laboratory, Guizhou Medical University Affiliated Hospital, Guizhou, China) for assistance in correcting the manuscript.

\section{Funding}

Not applicable.

\section{Availability of data and materials}

Data sharing is not applicable to this article, as no data sets were generated or analyzed during the current study.

\section{Authors' contributions}

XZ and DT designed the theme of the review. JW, YL and CC retrieved the relevant literature. $\mathrm{XS}$ wrote and reviewed the article.

\section{Ethics approval and consent to participate}

Not applicable.

\section{Patient consent for publication}

Not applicable.

\section{Competing interests}

The authors declare that they have no competing interests.

\section{References}

1. Zeng X, Zhang Y, Yang L, Xu H, Zhang T, An R and Zhu K: Association between RAD51 $135 \mathrm{G} / \mathrm{C}$ polymorphism and risk of 3 common gynecological cancers: A meta-analysis. Medicine (Baltimore) 97: e11251, 2018.

2. Rodon J, Dienstmann R, Serra V and Tabernero J: Development of PI3K inhibitors: Lessons learned from early clinical trials. Nat Rev Clin Oncol 10: 143-153, 2013.

3. Barra F, Evangelisti G, Ferro Desideri L, Di Domenico S, Ferraioli D, Vellone VG, De Cian F and Ferrero S: Investigational $\mathrm{PI} 3 \mathrm{~K} / \mathrm{AKT} / \mathrm{mTOR}$ inhibitors in development for endometrial cancer. Expert Opin Investig Drugs 28: 131-142, 2019.

4. Lu R, Yang Z, Xu G and Yu S: miR-338 modulates proliferation and autophagy by PI3K/AKT/mTOR signaling pathway in cervical cancer. Biomed Pharmacother 105: 633-644, 2018.

5. Zhang X, Zhou Y and Gu YE: Tanshinone IIA induces apoptosis of ovarian cancer cells in vitro and in vivo through attenuation of PI3K/AKT/JNK signaling pathways. Oncol Lett 17: 1896-1902, 2019.

6. Fruman DA, Meyers RE and Cantley LC: Phosphoinositide kinases. Annu Rev Biochem 67: 481-507, 1998.

7. Vanhaesebroeck B, Guillermet-Guibert J, Graupera M and Bilanges B: The emerging mechanisms of isoform-specific PI3K signalling. Nat Rev Mol Cell Biol 11: 329-341, 2010.

8. Guo H, German P, Bai S, Barnes S, Guo W, Qi X, Lou H, Liang J, Jonasch E, Mills GB and Ding Z: The PI3K/AKT pathway and renal cell carcinoma. J Genet Genomicsbao 42: 343-353, 2015.

9. Osaki M, Oshimura M and Ito H: PI3K-Akt pathway: Its functions and alterations in human cancer. Apoptosis 9: 667-676, 2004.

10. Auger KR, Serunian LA, Soltoff SP, Libby P and Cantley LC: PDGF-dependent tyrosine phosphorylation stimulates production of novel polyphosphoinositides in intact cells. Cell 57: $167-175,1989$.

11. Ruderman NB, Kapeller R, White MF and Cantley LC: Activation of phosphatidylinositol 3-kinase by insulin. Proc Natl Acad Sci USA 87: 1411-1415, 1990.

12. Fruman DA and Rommel C: PI3K and cancer: Lessons, challenges and opportunities. Nat Rev Drug Discov 13: 140-156, 2014.

13. Samuels $Y$ and Ericson K: Oncogenic PI3K and its role in cancer. Curr Opin Oncol 18: 77-82, 2006. 
14. Engelman JA: Targeting PI3K signalling in cancer: Opportunities, challenges and limitations. Nat Rev Cancer 9: 550-562, 2009.

15. Vadas O, Burke JE, Zhang X, Berndt A and Williams RL: Structural basis for activation and inhibition of class I phosphoinositide 3-kinases. Sci Signal 4: re2, 2011.

16. Dbouk HA, Khalil BD, Wu H, Shymanets A, Nurnberg B and Backer JM: Characterization of a tumor-associated activating mutation of the p110ß PI 3-kinase. PLoS One 8: e63833, 2013.

17. Zhang X, Vadas O, Perisic O, Anderson KE, Clark J, Hawkins PT, Stephens LR and Williams RL: Structure of lipid kinase p110 $3 / \mathrm{p} 85 \beta$ elucidates an unusual SH2-domain-mediated inhibitory mechanism. Mol Cell 41: 567-578, 2011.

18. Jaiswal BS, Janakiraman V, Kljavin NM, Chaudhuri S, Stern HM Wang W, Kan Z, Dbouk HA, Peters BA, Waring P, et al: Somatic mutations in p85alpha promote tumorigenesis through class IA PI3K activation. Cancer Cell 16: 463-474, 2009.

19. Cheung LW, Hennessy BT, Li J, Yu S, Myers AP, Djordjevic B, Lu Y, Stemke-Hale K, Dyer MD, Zhang F, et al: High frequency of PIK3R1 and PIK3R2 mutations in endometrial cancer elucidates a novel mechanism for regulation of PTEN protein stability. Cancer Discov 1: 170-185, 2011.

20. Sun M, Hillmann P, Hofmann BT, Hart JR and Vogt PK: Cancer-derived mutations in the regulatory subunit p85alpha of phosphoinositide 3-kinase function through the catalytic subunit p110alpha. Proc Natl Acad Sci USA 107: 15547-15552, 2010.

21. Graupera M, Guillermet-Guibert J,Foukas LC, Phng LK, Cain RJ, Salpekar A, Pearce W, Meek S, Millan J, Cutillas PR, et al: Angiogenesis selectively requires the p110alpha isoform of PI3K to control endothelial cell migration. Nature 453: 662-666, 2008

22. Graupera $M$ and Potente M: Regulation of angiogenesis by PI $3 \mathrm{~K}$ signaling networks. Exp Cell Res 319: 1348-1355, 2013.

23. Hirsch E, Ciraolo E, Franco I, Ghigo A and Martini M: PI3K in cancer-stroma interactions: Bad in seed and ugly in soil. Oncogene 33: 3083-3090, 2014.

24. Kinross KM, Montgomery KG, Kleinschmidt M, Waring P Ivetac I, Tikoo A, Saad M, Hare L, Roh V, Mantamadiotis T, et al: An activating Pik3ca mutation coupled with Pten loss is sufficient to initiate ovarian tumorigenesis in mice. J Clin Invest 122 553-557, 2012

25. Toulany M, Maier J, Iida M, Rebholz S, Holler M, Grottke A, Jüker M, Wheeler DL, Rothbauer U and Rodemann HP: Akt1 and Akt3 but not Akt2 through interaction with DNA-PKcs stimulate proliferation and post-irradiation cell survival of K-RAS-mutated cancer cells. Cell Death Discov 3: 17072, 2017.

26. Carnero A, Blanco-Aparicio C, Renner O, Link W and Leal JF: The PTEN/PI3K/AKT signalling pathway in cancer, therapeutic implications. Curr Cancer Drug Targets 8: 187-198, 2008.

27. Tokunaga E, Oki E, Egashira A, Sadanaga N, Morita M, Kakeji Y and Maehara Y: Deregulation of the Akt pathway in human cancer. Curr Cancer Drug Targets 8: 27-36, 2008.

28. Manning BD and Toker A: AKT/PKB signaling: Navigating the network. Cell 169: 381-405, 2017.

29. Alessi DR, James SR, Downes CP, Holmes AB, Gaffney PR, Reese CB and Cohen P: Characterization of a 3-phosphoinositide-dependent protein kinase which phosphorylates and activates protein kinase Balpha. Curr Biol 7: 261-269, 1997.

30. Andjelković M, Alessi DR, Meier R, Fernandez A, Lamb NJ, Frech M, Cron P, Cohen P, Lucocq JM and Hemmings BA: Role of translocation in the activation and function of protein kinase B. J Biol Chem 272: 31515-31524, 1997.

31. Girardi C, James P, Zanin S, Pinna LA and Ruzzene M: Differential phosphorylation of Akt 1 and Akt 2 by protein kinase CK2 may account for isoform specific functions. Biochim Biophys Acta 1843: 1865-1874, 2014.

32. Thorpe LM, Yuzugullu H and Zhao JJ: PI3K in cancer: Divergent roles of isoforms, modes of activation and therapeutic targeting. Nat Rev Cancer 15: 7-24, 2015.

33. Wong KK, Engelman JA and Cantley LC: Targeting the PI $3 K$ signaling pathway in cancer. Curr Opin Genet Dev 20: 87-90, 2010

34. Carpten JD, Faber AL, Horn C, Donoho GP, Briggs SL, Robbins CM, Hostetter G, Boguslawski S, Moses TY, Savage S, et al: A transforming mutation in the pleckstrin homology domain of AKT1 in cancer. Nature 448: 439-444, 2007.

35. Mazloumi Gavgani F, Smith Arnesen V, Jacobsen RG, Krakstad C, Hoivik EA and Lewis AE: Class I phosphoinositide 3 -Kinase PIK3CA/p110 $\alpha$ and PIK3CB/p110 $\beta$ isoforms in endometrial cancer. Int J Mol Sci 19: pii: E3931, 2018.

36. Prat J, Gallardo A, Cuatrecasas M and Catasús L: Endometrial carcinoma: Pathology and genetics. Pathology 39: 72-87, 2007.
37. Lee TY, Martinez-Outschoorn UE, Schilder RJ, Kim CH, Richard SD, Rosenblum NG and Johnson JM: Metformin as a therapeutic target in endometrial cancers. Front Oncol 8: 341, 2018.

38. Hua L, Zhang L, Zhang X and Cui Z: PI3K/AKT/mTOR pathway promotes progestin resistance in endometrial cancer cells by inhibition of autophagy. Onco Targets Ther 10: 2865-2871, 2017.

39. Lu KH, Wu W, Dave B, Slomovitz BM, Burke TW, Munsell MF, Broaddus RR and Walker CL: Loss of tuberous sclerosis complex-2 function and activation of mammalian target of rapamycin signaling in endometrial carcinoma. Clin Cancer Res 14: 2543-2550, 2008.

40. Shen Q, Stanton ML, Feng W, Rodriguez ME, Ramondetta L, Chen L, Brown RE and Duan X: Morphoproteomic analysis reveals an overexpressed and constitutively activated phospholipase D1-mTORC2 pathway in endometrial carcinoma. Int J Clin Exp Pathol 4: 13-21, 2010.

41. Cancer Genome Atlas Research Network, Kandoth C, Schultz N, Cherniack AD, Akbani R, Liu Y, Shen H, Robertson AG, Pashtan I, Shen R, et al: Integrated genomic characterization of endometrial carcinoma. Nature 497: 67-73, 2013.

42. Shi B, Wang Y, Zhao R, Long X, Deng W and Wang Z: Bone marrow mesenchymal stem cell-derived exosomal miR-21 protects C-kit+ cardiac stem cells from oxidative injury through the PTEN/PI3K/Akt axis. PLoS One 13: e0191616, 2018.

43. Pavlidou A and Vlahos NF: Molecular alterations of PI3K/Akt/mTOR pathway: A therapeutic target in endometrial cancer. ScientificWorldJournal 2014: 709736, 2014.

44. Sun H, Enomoto T, Fujita M, Wada H, Yoshino K, Ozaki K, Nakamura T and Murata Y: Mutational analysis of the PTEN gene in endometrial carcinoma and hyperplasia. Am J Clin Pathol 115: 32-38, 2001.

45. Kanamori Y, Kigawa J, Itamochi H, Shimada M, Takahashi M, Kamazawa S, Sato S, Akeshima R and Terakawa N: Correlation between loss of PTEN expression and Akt phosphorylation in endometrial carcinoma. Clin Cancer Res 7: 892-895, 2001.

46. Kong D, Suzuki A, Zou TT, Sakurada A, Kemp LW, Wakatsuki S, Yokoyama T, Yamakawa H, Furukawa T, Sato M, et al: PTEN1 is frequently mutated in primary endometrial carcinomas. Nat Genet 17: 143-144, 1997.

47. Quddus MR, Ologun BA, Sung CJ, Steinhoff MM and Lawrence WD: Utility of PTEN expression of endometrial 'surface epithelial changes' and underlying atypical endometrial hyperplasia. Int J Gynecol Pathol 28: 471-476, 2009.

48. Mutter GL: Pten, a protean tumor suppressor. Am J Pathol 158 1895-1898, 2001

49. Bansal N, Yendluri V and Wenham RM: The molecular biology of endometrial cancers and the implications for pathogenesis, classification, and targeted therapies. Cancer Control 16: 8-13, 2009.

50. Bertelsen BI, Steine SJ, Sandvei R, Molven A and Laerum OD Molecular analysis of the PI3K-AKT pathway in uterine cervical neoplasia: Frequent PIK3CA amplification and AKT phosphorylation. Int J Cancer 118: 1877-1883, 2006.

51. Oh KJ, Kalinina A, Park NH and Bagchi S: Deregulation of eIF4E: 4E-BP1 in differentiated human papillomavirus-containing cells leads to high levels of expression of the E7 oncoprotein. J Virol 80: 7079-7088, 2006.

52. Schwarz JK, Payton JE, Rashmi R, Xiang T, Jia Y, Huettner P, Rogers BE, Yang Q, Watson M, Rader JS and Grigsby PW: Pathway-specific analysis of gene expression data identifies the PI3K/Akt pathway as a novel therapeutic target in cervical cancer. Clin Cancer Res 18: 1464-1471, 2012.

53. Rashmi R, DeSelm C, Helms C, Bowcock A, Rogers BE, Rader JL, Grigsby PW and Schwarz JK: AKT inhibitors promote cell death in cervical cancer through disruption of mTOR signaling and glucose uptake. PLoS One 9: e92948, 2014.

54. Isakoff SJ, Engelman JA, Irie HY, Luo J, Brachmann SM, Pearline RV, Cantley LC and Brugge JS: Breast cancer-associated PIK3CA mutations are oncogenic in mammary epithelial cells. Cancer Res 65: 10992-11000, 2005.

55. Bader AG, Kang S and Vogt PK: Cancer-specific mutations in PIK3CA are oncogenic in vivo. Proc Natl Acad Sci USA 103: 1475-1479, 2006

56. Zhao JJ, Liu Z, Wang L, Shin E, Loda MF and Roberts TM: The oncogenic properties of mutant p110alpha and p110beta phosphatidylinositol 3-kinases in human mammary epithelial cells. Proc Natl Acad Sci USA 102: 18443-18448, 2005.

57. Gymnopoulos M,Elsliger MA and Vogt PK: Rare cancer-specific mutations in PIK3CA show gain of function. Proc Natl Acad Sci USA 104: 5569-5574, 2007 
58. Ocana A, Vera-Badillo F, Al-Mubarak M, Templeton AJ, Corrales-Sanchez V, Diez-Gonzalez L, Cuenca-Lopez MD, Seruga B, Pandiella A and Amir E: Activation of the $\mathrm{PI} 3 \mathrm{~K} / \mathrm{mTOR} / \mathrm{AKT}$ pathway and survival in solid tumors: Systematic review and meta-analysis. PLoS One 9: e95219, 2014

59. Grigsby P, Elhammali A, Ruiz F, Markovina S, McLellan MD Miller CA, Chundury A, Ta NL, Rashmi R, Pfeifer JD, et al: Clinical outcomes and differential effects of PI3K pathway mutation in obese versus non-obese patients with cervical cancer. Oncotarget 9: 4061-4073, 2017.

60. Bosch FX, Lorincz A, Muñoz N, Meijer CJ and Shah KV: The causal relation between human papillomavirus and cervical cancer. J Clin Pathol 55: 244-265, 2002.

61. Libby G, Donnelly LA, Donnan PT, Alessi DR, Morris AD and Evans JM: New users of metformin are at low risk of incident cancer: A cohort study among people with type 2 diabetes. Diabetes Care 32: 1620-1625, 2009.

62. Eskander RN and Tewari KS: Exploiting the therapeutic potential of the PI3K-AKT-mTOR pathway in enriched populations of gynecologic malignancies. Expert Rev Clin Pharmacol 7: 847-858, 2014.

63. Ko J, Lee YH, Hwang SY, Lee YS, Shin SM, Hwang JH, Kim J, Kim YW, Jang SW, Ryoo ZY, et al: Identification and differential expression of novel human cervical cancer oncogene HCCR-2 in human cancers and its involvement in p53 stabilization. Oncogene 22: 4679-4689, 2003.

64. Cho GW, Shin SM, Namkoong H, Kim HK, Ha SA, Hur SY Kim TE, Chai YG and Kim JW: The phosphatidylinosito 3-kinase/Akt pathway regulates the HCCR-1 oncogene expression. Gene 384: 18-26, 2006

65. Gui T and Shen K: The epidermal growth factor receptor as a therapeutic target in epithelial ovarian cancer. Cancer Epidemiol 36: 490-496, 2012.

66. Siegel RL, Miller KD and Jemal A: Cancer statistics, 2016. CA Cancer J Clin 66: 7-30, 2016

67. Mabuchi S, Kuroda H, Takahashi R and Sasano T: The $\mathrm{PI} 3 \mathrm{~K} / \mathrm{AKT} / \mathrm{mTOR}$ pathway as a therapeutic target in ovarian cancer. Gynecol Oncol 137: 173-179, 2015.

68. Levine DA, Bogomolniy F, Yee CJ, Lash A, Barakat RR, Borgen PI and Boyd J: Frequent mutation of the PIK3CA gene in ovarian and breast cancers. Clin Cancer Res 11: 2875-2878, 2005.

69. Andorfer P, Heuwieser A, Heinzel A, Lukas A, Mayer B and Perco P: Vascular endothelial growth factor A as predictive marker for mTOR inhibition in relapsing high-grade serous ovarian cancer. BMC Syst Biol 10: 33, 2016.

70. Cheaib B, Auguste A and Leary A: The PI3K/Akt/mTOR pathway in ovarian cancer: Therapeutic opportunities and challenges. Chin J Cancer 34: 4-16, 2015.

71. Mabuchi S, Kawase C, Altomare DA, Morishige K, Sawada K, Hayashi M, Tsujimoto M, Yamoto M, Klein-Szanto AJ, Schilder RJ, et al: mTOR is a promising therapeutic target both in cisplatin-sensitive and cisplatin-resistant clear cell carcinoma of the ovary. Clin Cancer Res 15: 5404-5413, 2009.

72. Di Nicolantonio F, Arena S, Tabernero J, Grosso S, Molinari F, Macarulla T, Russo M, Cancelliere C, Zecchin D, Mazzucchelli L, et al: Deregulation of the PI3K and KRAS signaling pathways in human cancer cells determines their response to everolimus. J Clin Invest 120: 2858-2866, 2010.

73. Altomare DA, Hui QW, Skele KL, De Rienzo A, Klein-Szanto AJ, Godwin AK and Testa JR: AKT and mTOR phosphorylation is frequently detected in ovarian cancer and can be targeted to disrupt ovarian tumor cell growth. Oncogene 23: 5853-5857, 2004.

74. Borman SM, Christian PJ, Sipes IG and Hoyer PB: Ovotoxicity in female Fischer rats and B6 mice induced by low-dose exposure to three polycyclic aromatic hydrocarbons: Comparison through calculation of an ovotoxic index. Toxicol Appl Pharmacol 167: 191-198, 2000.

75. Sobinoff AP, Nixon B, Roman SD and McLaughlin EA: Staying alive: PI3K pathway promotes primordial follicle activation and survival in response to $3 \mathrm{MC}$-induced ovotoxicity. Toxicol Sci 128: 258-271, 2012.

76. Cancer Genome Atlas Research Network: Integrated genomic analyses of ovarian carcinoma. Nature 474: 609-615, 2011.

77. Dobbin ZC and Landen CN: The importance of the PI3K/AKT/MTOR pathway in the progression of ovarian cancer. Int J Mol Sci 14: 8213-8227, 2013
78. Cho D: Novel targeting of phosphatidylinositol 3-kinase and mammalian target of rapamycin in renal cell carcinoma. Cancer J 19: 311-315, 2013

79. O'Reilly KE, Rojo F, She QB, Solit D, Mills GB, Smith D, Lane H, Hofmann F, Hicklin DJ, Ludwig DL, et al: mTOR inhibition induces upstream receptor tyrosine kinase signaling and activates Akt. Cancer Res 66: 1500-1508, 2006.

80. Figlin RA, Kaufmann I and Brechbiel J: Targeting PI3K and mTORC2 in metastatic renal cell carcinoma: New strategies for overcoming resistance to VEGFR and mTORC1 inhibitors. Int J Cancer 133: 788-796, 2013.

81. Dillon RL, Marcotte R, Hennessy BT, Woodgett JR, Mills GB and Muller WJ: Akt1 and akt2 play distinct roles in the initiation and metastatic phases of mammary tumor progression. Cancer Res 69: 5057-5064, 2009.

82. Endersby R, Zhu X, Hay N, Ellison DW and Baker SJ: Nonredundant functions for Akt isoforms in astrocyte growth and gliomagenesis in an orthotopic transplantation model. Cancer Res 71: 4106-4116, 2011.

83. Behbakht K, Sill MW, Darcy KM, Rubin SC, Mannel RS, Waggoner S, Schilder RJ, Cai KQ, Godwin AK and Alpaugh RK: Phase II trial of the mTOR inhibitor, temsirolimus and evaluation of circulating tumor cells and tumor biomarkers in persistent and recurrent epithelial ovarian and primary peritoneal malignancies: A gynecologic oncology group study. Gynecol Oncol 123: 19-26, 2011

84. Takano M, Kikuchi Y, Kudoh K, Goto T, Furuya K, Kikuchi R, Kita T, Fujiwara K, Shiozawa T and Aoki D: Weekly administration of temsirolimus for heavily pretreated patients with clear cell carcinoma of the ovary: A report of six cases. Int J Clin Oncol 16: 605-609, 2011

85. Pétignylechartier C, Duboc C, Jebahi A, Louis MH, Abeilard E, Denoyelle C, Gauduchon P, Poulain L and Villedieu M: The mTORC1/2 Inhibitor AZD8055 strengthens the efficiency of the mek inhibitor trametinib to reduce the Mcl-1/[Bim and Puma] ratio and to sensitize ovarian carcinoma cells to ABT-737. Mol Cancer Ther 16: 102-115, 2017.

86. Itamochi H, Oishi T, Oumi N, Takeuchi S, Yoshihara K, Mikami M, Yaegashi N, Terao Y, Takehara K, Ushijima K, et al: Whole-genome sequencing revealed novel prognostic biomarkers and promising targets for therapy of ovarian clear cell carcinoma. Br J Cancer 117: 717-724, 2017.

87. Slomovitz BM and Coleman RL: The PI3K/AKT/mTOR pathway as a therapeutic target in endometrial cancer. Clin Cancer Res 18: 5856-5864, 2012

88. Sahoo SS, Lombard JM, Ius Y, O'Sullivan R, Wood LG, Nahar P, Jaaback K and Tanwar PS: Adipose-Derived VEGF-mTOR signaling promotes endometrial hyperplasia and cancer: Implications for obese women. Mol Cancer Res 16: 309-321, 2018.

89. Philip CA, Laskov I, Beauchamp MC, Marques M, Amin O, Bitharas J, Kessous R, Kogan L, Baloch T, Gotlieb WH and Yasmeen A: Inhibition of PI3K-AKT-mTOR pathway sensitizes endometrial cancer cell lines to PARP inhibitors. BMC Cancer 17: 638, 2017.

90. Han C, Altwerger G, Menderes G, Haines K, Feinberg J, Lopez S, Manzano A, Varughese J and Santin AD: Novel targeted therapies in ovarian and uterine carcinosarcomas. Discov Med 25: 309-319, 2018.

91. Tamura R, Yoshihara K, Saito T, Ishimura R, MartínezLedesma JE, Xin H, Ishiguro T, Mori Y, Yamawaki K, Suda K, et al: Novel therapeutic strategy for cervical cancer harboring FGFR3-TACC3 fusions. Oncogenesis 7: 4, 2018.

92. Carneiro BA, Elvin JA, Kamath SD, Ali SM, Paintal AS, Restrepo A, Berry E, Giles FJ and Johnson ML: FGFR3-TACC3: A novel gene fusion in cervical cancer. Gynecol Oncol Rep 13: 53-56, 2015

93. Bian X, Gao J, Luo F, Rui C, Zheng T, Wang D, Wang Y, Roberts TM, Liu P, Zhao JJ and Cheng H: PTEN deficiency sensitizes endometrioid endometrial cancer to compound PARP-PI3K inhibition but not PARP inhibition as monotherapy. Oncogene 37: 341-351, 2018.

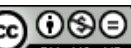

This work is licensed under a Creative Commons Attribution-NonCommercial-NoDerivatives 4.0 International (CC BY-NC-ND 4.0) License. 